\title{
Is there a relationship between language switching and executive functions in bilingualism? Introducing a within-group analysis approach
}

\author{
Anna Soveri ${ }^{1}{ }^{*}$ Antoni Rodriguez-Fornells ${ }^{2,3,4}$ and Matti Laine ${ }^{1}$ \\ 1 Department of Psychology and Logopedics, Abo Akademi University, Turku, Finland \\ 2 Cognition and Brain Plasticity Group, Bellvitge Biomedical Research Institute, L'Hospitalet de Llobregat, Spain \\ ${ }^{3}$ Department of Basic Psychology, Campus Bellvitge, University of Barcelona, L'Hospitalet de Llobregat, Spain \\ ${ }^{4}$ Catalan Institution for Research and Advanced Studies, Barcelona, Spain
}

\section{Edited by:}

Ingrid Christoffels, University of Leiden, Netherlands

Reviewed by:

Mireia Hernandez, University Pompeu Fabra, Spain

Lorenza S. Colzato, Leiden University, Netherlands

Zofia Wodniecka, Jagiellonian

University, Poland

${ }^{*}$ Correspondence:

Anna Soveri, Department of

Psychology and Logopedics, Abo

Akademi University, 20500 Turku,

Finland.

e-mail:anna.soveri@abo.fi
Several studies have suggested a bilingual advantage in executive functions, presumably due to bilinguals' massive practice with language switching that requires executive resources, but the results are still somewhat controversial. Previous studies are also plagued by the inherent limitations of a natural groups design where the participant groups are bound to differ in many ways in addition to the variable used to classify them. In an attempt to introduce a complementary analysis approach, we employed multiple regression to study whether the performance of 30- to 75-year-old Finnish-Swedish bilinguals ( $N=38$ ) on tasks measuring different executive functions (inhibition, updating, and set shifting) could be predicted by the frequency of language switches in everyday life (as measured by a language switching questionnaire), L2 age of acquisition, or by the self-estimated degree of use of both languages in everyday life. Most consistent effects were found for the set shifting task where a higher rate of everyday language switches was related to a smaller mixing cost in errors. Mixing cost is thought to reflect top-down management of competing task sets, thus resembling the bilingual situation where decisions of which language to use has to be made in each conversation. These findings provide additional support to the idea that some executive functions in bilinguals are affected by a lifelong experience in language switching and, perhaps even more importantly, suggest a complementary approach to the study of this issue.

Keywords: bilingualism, executive functions, inhibition, set shifting, updating, language switching

\section{INTRODUCTION}

Executive functions is a broad, still somewhat undefined, concept that involves abilities that make independent, purposive, self-serving, and socially responsible behavior possible (Lezak, 1995). In an attempt to categorize the available concepts and measures in a coherent fashion, Miyake and his colleagues investigated the psychometric relationships between tasks that are commonly used to assess executive functions (Miyake et al., 2000; Friedman and Miyake, 2004; Friedman et al., 2006). Their findings suggest the existence of three major, separable executive functions: the "inhibition" of unwanted responses, the "shifting" between tasks and mental sets (also called "flexibility"), and the "updating" (and monitoring of) working memory (WM) representations. Research during the last three decades has suggested that bilingualism can enhance certain executive functions (for a review see, e.g., Bialystok, 2009).

Several studies comparing groups of monolingual vs. bilingual individuals (both children and adults) have shown a bilingual advantage in executive functions, particularly in the ability to inhibit irrelevant information (Bialystok and Majumder, 1998; Bialystok, 1999; Bialystok and Martin, 2004; Bialystok et al., 2004, 2006b, 2008; Carlson and Meltzoff, 2008; Costa et al., 2008; Bialystok and Viswanathan, 2009; Soveri et al., 2011). Bilingual advantages have also been reported in the ability to efficiently process a mix of dif- ferent types of trials that either require or do not require inhibition of conflicting information (Bialystok et al., 2006b; Bialystok and Viswanathan, 2009; Costa et al., 2009; see also Martin-Rhee and Bialystok, 2008). Moreover, bilinguals have been reported to excel monolinguals in their ability to store information in WM (Bialystok et al., 2004).

The bilingual advantage in executive functions is thought to stem from the fact that managing two languages requires executive resources in the form of selection of the relevant language and inhibition of the language not in use at that moment (Green, 1998; Meuter and Allport, 1999; Rodriguez-Fornells et al., 2006; Abutalebi and Green, 2007; Moreno et al., 2008; Bialystok et al., 2009; Ye and Zhou, 2009). Since bilinguals have a lifelong experience in controlling their two languages, they should have received more practice than monolinguals in processes that engage executive functions. This idea is supported by previous studies suggesting that earlier second language (L2) acquisition, higher levels of language proficiency in both languages, and a more balanced use of both languages may have positive effects on executive performance in bilinguals (e.g., Bialystok et al., 2006a; Carlson and Meltzoff, 2008). Further, Costa et al. (2009) hypothesized that the bilingual advantage in executive functions may be related to the degree to which the bilingual uses both languages in conversations in everyday life. Bilinguals 
who tend to mix languages throughout the day may receive more practice in monitoring processes (in terms of selecting which language to use) and therefore show better executive performance than bilinguals from diglossic sociolinguistic environments where the languages are held separate. Albeit speculative, these considerations highlight the need to relate specific aspects of everyday bilingual behavior to performance on executive test measures.

The exact mechanisms underlying the bilingual executive advantage are not clear. Costa et al. (2009) suggested that the bilingual advantage in inhibition tasks may be caused by the bilinguals having to inhibit the language not in use at a given moment, while their more efficient processing of a mix of different types of trials may stem from the fact that bilinguals constantly need to keep track of both languages in order to select the appropriate language for the situation (see also Bialystok et al., 2009). Further, Colzato et al. (2008) suggested that the bilingual advantage is related to reactive inhibition, a process caused by facilitation of the relevant information in a conflict resolution situation, and not to active inhibition, a process in which irrelevant information is actively inhibited. Colzato et al. (2008) proposed that the bilingual advantage in executive functions is not a result of constantly inhibiting the irrelevant language, but of better selection of the relevant language from the competing irrelevant language.

Although the possible bilingual advantage in executive functions has been assessed in several studies, the research field has solely relied on quasi-experimental designs where bilinguals are compared to monolinguals. Such designs lack the key component of experimental designs which is the randomization of participants into the different groups. As a consequence, it is hard to rule out the role of possible confounding factors that may covary with the variable of interest, i.e., language background.

The present study was an attempt to introduce a complementary analysis approach to study the bilingual advantage in executive functions and its underlying mechanisms. We employed multiple regression in a sample of bilingual Finnish-Swedish adults to investigate whether interindividual differences in five bilingualism-related background factors (language switching, contextual switches, unintended switches, use of both languages in everyday life, and age of L2 acquisition) would be related to the participants' performance on tasks measuring three executive functions (inhibition, updating, and set shifting; see Miyake et al., 2000). To measure our bilinguals' everyday language switching tendencies, we employed a Bilingual Switching Questionnaire (BSWQ; Rodriguez-Fornells et al., submitted). We hypothesized that if the proposed bilingual executive advantage indeed stems from practice in language control, i.e., selecting the target language and/or inhibiting the non-target language, the frequency of behaviors calling for such cognitive processes should correlate with executive measures.

\section{MATERIALS AND METHODS \\ PARTICIPANTS}

The present study employed 38 (12 men; 26 women) neurologically healthy, right-handed Finnish-Swedish bilinguals between 30 and 75 years of age $(M=52.84, \mathrm{SD}=14.96$; Table 1$)$. On the average, they were quite highly educated $(M=15.45$ years of education, $\mathrm{SD}=4.14)^{1}$. All participants were early simultaneous

${ }^{1}$ The participants in the present study were partly the same as in Soveri et al. (2011). bilinguals, i.e., they had learned both languages before the age of 7 (Swedish: $M=3.08$ years of age, $\mathrm{SD}=1.74$, Finnish: $M=2.78$, $\mathrm{SD}=1.56)$ and since then used both languages throughout their lives. To ensure that they had balanced skills in both of their languages, they were asked to grade their language skills in Finnish and Swedish on a scale from 0 to 6 , where 0 corresponded to no skills in that particular language and 6 to skills at a native level (Table 2). There was no significant difference between their Finnish and Swedish speaking skills, reading skills, writing skills, or speech comprehension skills [in all cases, $t(37)<1$ ].

\section{TASKS AND QUESTIONNAIRES \\ The Simon task}

The first measure of inhibition that we employed was the Simon task (Simon and Rudell, 1967). This task has been suggested to tap both reactive and active inhibition (Colzato et al., 2008) and several studies have shown a bilingual advantage on this task (Bialystok et al., 2004, 2008; Martin-Rhee and Bialystok, 2008; but see Morton and Harper, 2007; Namazi and Thordardottir, 2010). In this task, a blue or a red square appeared on either the left or the right side of the screen. The participants were to push the left button each time a blue square appeared and the right button each time a red square appeared, irrespective of which side the square was presented on. On congruent trials, the response button was on the same side as the square and on incongruent trials, the square was on the opposite side of the response button, i.e., the irrelevant spatial information was conflicting with the correct response.

Table 1 | Demographics and scores on the BSWQ subscales.

\begin{tabular}{lrrr}
\hline & M & SD & Range \\
\hline Age in years & 52.8 & 15.0 & 30-75 \\
Years of education & 15.5 & 4.1 & $8-25$ \\
Everyday use of both languages in \% & 36.5 & 29.7 & $0-90$ \\
Age of L2 acquisition in years & 4.0 & 1.6 & $1-6$ \\
BSWQ: language switching (6-30 pts) & 14.1 & 3.0 & 8-19 \\
BSWO: contextual switches (3-15 pts) & 7.8 & 2.7 & 3-13 \\
BSWQ: unintended switches (3-15 pts) & 6.0 & 2.0 & 3-10 \\
\hline
\end{tabular}

Table 2 | Summary of the participants' estimations of their language skills.

\begin{tabular}{lll}
\hline Language & $\boldsymbol{M}$ & SD \\
\hline FINNISH & & \\
Speaking & 5.68 & 0.47 \\
Reading & 5.74 & 0.60 \\
Writing & 5.39 & 0.72 \\
Speech comprehension & 5.82 & 0.39 \\
SWEDISH & & \\
Speaking & 5.71 & 0.52 \\
Reading & 5.74 & 0.60 \\
Writing & 5.32 & 0.96 \\
Speech comprehension & 5.82 & 0.39
\end{tabular}


The present task version included 100 trials of which half were congruent and half incongruent. The presentation order of the trials was randomized separately for each subject. The trials were divided into four blocks with a 5-s break in-between. Before starting the actual test, every subject received a practice sequence. Each trial began with a fixation cross at the center of the computer screen. The cross remained on the screen for $800 \mathrm{~ms}$ after which it vanished and there was a 250-ms blank interval. The blank interval was followed by a square (either red or blue) which remained on the screen for $1000 \mathrm{~ms}$ if no response was given. After the square vanished, the screen was blank for $500 \mathrm{~ms}$. The differences in RTs and error rates between the incongruent and congruent trials (the Simon effect) were used as the dependent measures on this task. These variables reflect the extra processing cost of having to inhibit the incompatible spatial location of the stimulus ${ }^{2}$.

\section{The Flanker task}

The other measure of inhibition that we used was the Flanker task (adapted from Eriksen and Eriksen, 1974). A bilingual advantage has previously been found on a modified version of this task (Costa et al., 2008, 2009). In the present task version, five black arrows were presented in a horizontal line at the center of the screen. The task was to decide in which direction the arrow in the middle was pointing, irrespective of the direction of the other arrows (the flankers). On congruent trials, all the arrows pointed in the same direction and on incongruent trials, the flankers pointed in a different direction than the arrow in the middle.

The present task consisted of 50 congruent trials and 50 incongruent trials. The presentation order of the trials was randomized separately for each subject. The trials were divided into two blocks with a 5-s break in-between. Before starting the actual test, the participant received a practice sequence. Each trial began with a fixation cross at the center of the screen. The cross vanished after $800 \mathrm{~ms}$ and five arrows appeared in a horizontal line. The arrows remained on the screen for $800 \mathrm{~ms}$ if no response was given. This was followed by a blank interval of $500 \mathrm{~ms}$. The dependent measures on this task were the differences in RTs and error rates between incongruent and congruent trials (the Flanker effect). The difference variables are measures of the extra processing cost caused by inhibiting the conflicting flanker arrows.

\section{The spatial $\mathbf{N}$-back task}

Working memory updating was measured by a visuospatial version of the N-back task (adapted from Carlsson et al., 1998). N-back tasks have not been employed in previous bilingual research, but a study by Bialystok et al. (2004) indicated a smaller WM load effect in bilinguals in a modified Simon task. In the N-back task used in the present study, a white square was presented in one of eight possible locations on the screen. The participant was to remember the location of the previous square (1-back) or the one before the previous square (2-back).

${ }^{2}$ We also calculated the so-called Gratton effect (Gratton et al., 1992) that reflects the effect of the previous trial type (its compatibility with the current trial type) on performance on the current trial. Two measures were calculated: (a) the difference between incongruent to congruent and congruent to congruent trials, and (b) the difference between congruent to incongruent and incongruent to incongruent trials. The multiple regression models were, however, not significant for either of these variables.
The task used in the present study consisted of 80 one-back trials and 80 two-back trials. The trials were divided into two blocks with 80 trials each and with a 15 -s break in-between. Each block consisted of four sequences of 20 trials: two sequences with 1-back trials and two sequences with 2-back trials. Each sequence included 6 targets and 14 non-targets. The order of the sequences was 1-back, 2-back, 2-back, 1-back within the first block, and 2-back, 1-back, 1-back, 2-back within the second block. The presentation order of the trials was pseudorandomized. Before the actual task, the participant was requested to complete a practice sequence.

In the 1-back task, the participant pressed one of the two response buttons: the right one each time the square appeared in the same location as the previous square and the left one each time the location was different. On the 2-back task, the participant was asked to press the right button each time the square was in the same location as the square two trials back and the left button if the location was different. In the beginning of each sequence, the number " 1 " or " 2 " appeared at the center of the screen. Number " 1 " indicated a 1-back sequence and number " 2 " a 2-back sequence. The number remained on the screen for $5000 \mathrm{~ms}$ and was then replaced by a fixation cross in the middle of the screen and a square in one of eight possible locations. The square remained on the screen for $100 \mathrm{~ms}$. A new square appeared $3000 \mathrm{~ms}$ after the previous square had disappeared, irrespective of whether a response was given or not. The RT and error rate differences between 2-back and 1-back trials (N-back effect) were used as dependent variables, and reflect the cost of managing the increased demands on updating.

\section{The number-letter task}

Shifting abilities were assessed with the Number-letter task (adapted from Rogers and Monsell, 1995). This particular task has not been used in previous bilingualism research. In this task, a number-letter combination (e.g., 3A) appeared in one of two squares at the center of the screen. The task was to either determine if the number was even or odd or if the letter was a vowel or a consonant, depending on in which square the number-letter pair appeared. The squares thus served as cues for which task to perform. Each time the numberletter combination was in the upper box, the task was to determine the number and each time it appeared in the lower box, the task was to determine the letter.

The trials were divided into three different blocks with short breaks in-between. The first two blocks, with 32 trials in each, were single-task blocks, in which the number-letter combination was in the same square on all trials and no task switching was required (Block 1: in the upper square; Block 2: in the lower square). The third block was a mixed-tasks block with 32 switching trials and 48 repetition trials (the task was the same as in the previous trial). The 48 repetition trials included 24 trials in which the participant was asked to decide if the number was even or odd, and 24 trials where the participant was to decide if the letter was a vowel or a consonant. The task switching was unpredictable for the subject, as the number-letter combination appeared in the two squares randomly. The left button was to be pressed each time the number was even or the letter was a vowel, and the right button each time the number was odd or the letter was a consonant. Each block was preceded by a practice sequence. 
Each trial began with a 150-ms blank interval, after which a fixation cross appeared at the center of the screen. After $300 \mathrm{~ms}$, two small boxes appeared above each other at the center of the screen, with a number-letter combination in one of the boxes. The stimuli remained on the screen for $3000 \mathrm{~ms}$ if no response was given. There were two dependent measures for both RTs and error rates on this task. The first one was the switching cost that was defined as the performance difference between the repetition trials and switching trials in the mixed-tasks block. This reflects the cost of a temporary change in task sets. The second dependent variable was the mixing cost that was the performance difference on the single-task trials vs. the repetition trials in the mixed-tasks block. This reflects the cost of maintenance of attentional control in a context where two task sets are active.

\section{The Bilingual Switching Questionnaire}

All participants completed a Swedish translation of the BSWQ, a survey instrument developed by Rodriguez-Fornells et al. (submitted) for the study of individual differences in natural language switching. The questionnaire included 12 questions representing four subscales: (a) Tendencies to switch from Swedish to Finnish (e.g., "When I do not find a word in Swedish, I immediately tend to produce it in Finnish"), (b) Tendencies to switch from Finnish to Swedish (e.g., "When I do not find a word in Finnish, I immediately tend to produce it in Swedish"), (c) Contextual switches (e.g., "There are situations in which I always switch between languages"), and (d) Unintended switches (e.g., "It is difficult for me to control the language switches I make during a conversation (e.g., from Swedish to Finnish)"). The participants responded on a 5-point scale varying from never (1) to always (5). The construction and psychometric assessment of the original BSWQ and its four subscales on a large sample of bilingual Spanish-Catalan speakers is described in Rodriguez-Fornells et al. (submitted). Their paper also includes the original questionnaire and its translation in English.

Three measures from the BSWQ were used in the multiple regression analyses: language switching, contextual switches, and unintended switches. The language switching variable was created by adding up the points on the first two subscales (Tendencies to switch from Swedish to Finnish; Tendencies to switch from Finnish to Swedish).

Our hypotheses concerning the measures from the BSWQ were as follows. Regarding the language switching and contextual switches subscales, we predicted that the more a person switches languages in everyday life (a higher score on a subscale), the better the performance (a smaller processing cost) should be on the executive tasks, if the bilingual advantage in executive functioning stems from a lifelong experience in language switching. In contrast, one would not expect to find such a correlation between executive measures and unintended switches, as they may reflect temporary processes that induce lapses of attention.

\section{Other background tests and questionnaires}

All participants were asked to give their written informed consent and to fill out the Edinburgh Handedness Inventory (Oldfield, 1971). They also completed a background information sheet probing their date of birth, education, occupation, vision, hearing, possible reading difficulties, possible neurological and psychiatric illnesses, medication, subjective level of alertness, and possible alcohol intake during the 24 -h period preceding the testing. The participants were also asked to fill out a questionnaire concerning their language background and language skills. In this questionnaire, the participants were asked about their age of L2 acquisition, the languages they had used in written and spoken form during the last 3 years, and the frequency (in percent) with which they had used each language in everyday life. In order to obtain a measure of the everyday use of both languages, the percentage of the less frequently used language was subtracted from the percentage of the more frequently used language.

\section{STATISTICAL ANALYSES}

Multiple linear regression analyses were conducted for the processing cost in RTs and error rates (Table 3), separately for each executive task. Two models of predictors were employed. The first included three background factors, namely participant's age, the age of L2 acquisition, and the percentage of the everyday use of both languages. The second group of predictors included three measures from the BSWQ: the BSWQ language switching measure, the BSWQ contextual switches measure, and the BSWQ unintended switches measure. In both models, the predictors were inserted simultaneously to the analyses.

\section{RESULTS}

With regard to the processing cost in RTs (Tables 4 and 5), the multiple regression model with age, age of L2 acquisition, and everyday use of both languages was significant for the Simon effect, $F(3,36)=3.14, p=0.038$, and the mixing cost, $F(3,34)=3.95$, $p=0.017$, in the Number-letter task, and the model explained $15 \%$ (Adjusted $R^{2}=0.151$ ) of the variance in the Simon effect and $21 \%$ (Adjusted $R^{2}=0.207$ ) of the variance in the mixing cost. There was a significant association between the predictor age of L2 acquisi-

Table 3 | Performance on the executive tasks.

\begin{tabular}{|c|c|c|c|c|}
\hline & \multicolumn{2}{|c|}{$\mathrm{RT}$ in $\mathrm{ms}$} & \multicolumn{2}{|c|}{ Errors in \% } \\
\hline & $M$ & SD & $M$ & SD \\
\hline \multicolumn{5}{|l|}{ SIMONTASK } \\
\hline Congruent & 512 & 90 & 2.7 & 3.5 \\
\hline Incongruent & 557 & 90 & 3.4 & 3.8 \\
\hline Simon effect & 45 & 37 & 0.7 & 4.2 \\
\hline \multicolumn{5}{|l|}{ FLANKER TASK } \\
\hline Congruent & 501 & 69 & 0.6 & 1.6 \\
\hline Incongruent & 563 & 81 & 2.5 & 2.6 \\
\hline Flanker effect & 62 & 31 & 1.9 & 2.5 \\
\hline \multicolumn{5}{|l|}{ N-BACK TASK } \\
\hline 1-back & 816 & 170 & 5.5 & 4.4 \\
\hline 2-back & 1017 & 215 & 15.0 & 11.5 \\
\hline N-back effect & 201 & 155 & 9.5 & 9.8 \\
\hline \multicolumn{5}{|c|}{ NUMBER-LETTER TASK } \\
\hline Single-task trials & 668 & 120 & 1.9 & 2.7 \\
\hline Repetition trials & 1000 & 272 & 3.6 & 3.9 \\
\hline Switching trials & 1325 & 322 & 7.4 & 7.0 \\
\hline Switching cost & 325 & 139 & 3.8 & 6.1 \\
\hline Mixing cost & 333 & 209 & 1.7 & 4.0 \\
\hline
\end{tabular}


Table 4 | Summary of the multiple regression analyses: background variables as predictors of processing cost in RTs on the executive tasks.

\begin{tabular}{|c|c|c|c|c|c|}
\hline \multirow[t]{2}{*}{ Variable } & \multirow{2}{*}{$\begin{array}{l}\text { The Flanker effect } \\
B\end{array}$} & \multirow{2}{*}{$\begin{array}{l}\text { The Simon effect } \\
B\end{array}$} & \multirow{2}{*}{$\begin{array}{l}\text { The N-back effect } \\
B\end{array}$} & \multicolumn{2}{|c|}{ The number-letter task } \\
\hline & & & & $\begin{array}{l}\text { Switching cost } \\
B\end{array}$ & $\begin{array}{l}\text { Mixing cost } \\
B\end{array}$ \\
\hline Constant & $78.57 * *$ & -16.53 & 163.55 & 145.33 & -104.56 \\
\hline Age & 0.00 & 0.31 & -0.55 & 3.23 & 4.13 \\
\hline Age of L2 acquisition & -0.34 & $8.95^{*}$ & 7.12 & 6.64 & 37.63 \\
\hline$R^{2}$ & 0.16 & 0.22 & 0.04 & 0.15 & 0.28 \\
\hline$F$ & 2.13 & $3.14^{*}$ & 0.46 & 1.85 & $3.95^{*}$ \\
\hline
\end{tabular}

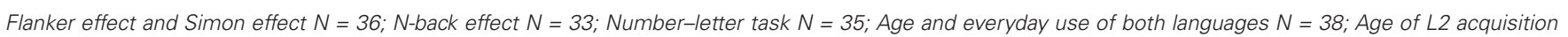
$N=37 .^{*}=p<0.05,{ }^{*}=p<0.01$.

Table 5 | Summary of the multiple regression analyses: background variables as predictors of processing cost in errors on the executive tasks.

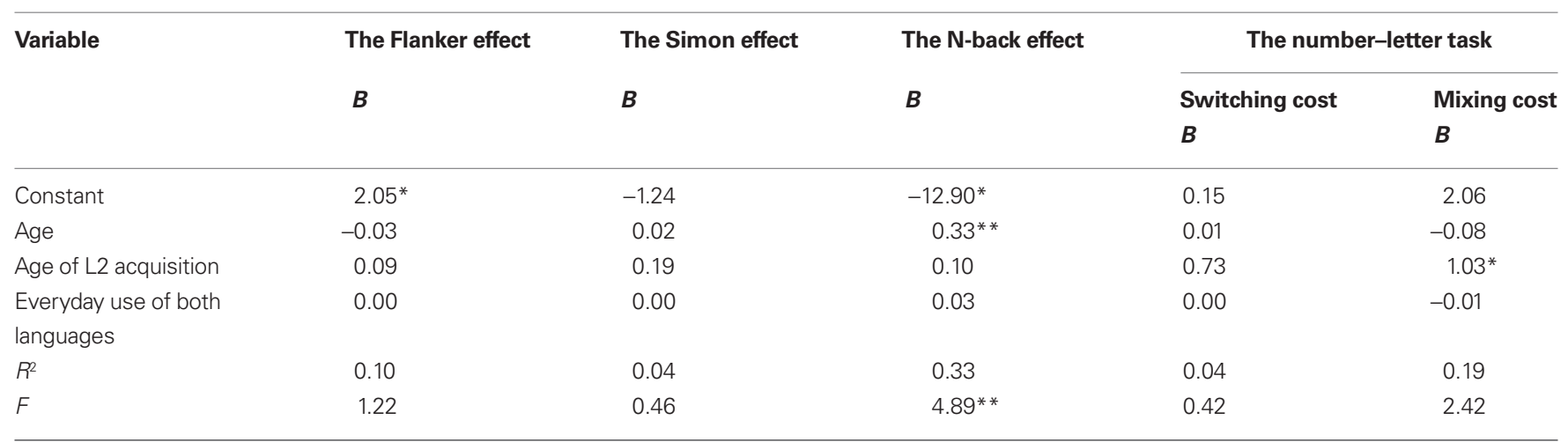

Flanker effect and Simon effect $N=36 ; N$-back effect $N=33 ;$ Number-letter task $N=35 ;$ Age and everyday use of both languages $N=38 ;$ Age of L2 acquisition $N=37 .^{*}=p<0.05,{ }^{* *}=p<0.01$.

tion and the Simon effect as the outcome variable, indicating that younger age of $\mathrm{L} 2$ acquisition resulted in a smaller Simon effect in RTs. Furthermore, all three predictors were marginally significant $(p<0.10)$ in predicting the mixing cost, so that younger age, earlier L2 acquisition, and a more balanced use of both languages in everyday life was associated with a smaller mixing cost. The multiple regression model with the three BSWQ predictors was significant for the mixing cost, $F(3,34)=2.91, p=0.050$, in the Numberletter task. The model explained $14 \%$ (Adjusted $R^{2}=0.144$ ) of the variance. None of the predictors, however, reached significance in this analysis.

The analyses on the processing cost in error rates (Tables 6 and 7 ) indicated that the multiple regression model with age, age of L2 acquisition, and everyday use of both languages was significant for the N-back effect, $F(3,33)=4.89, p=0.007$, and the model explained $26 \%$ (Adjusted $R^{2}=0.261$ ) of the variance. There was a significant association between the predictor age and the N-back effect as an outcome variable so that younger age resulted in a smaller N-back effect in errors. The results also showed that the multiple regression model with the three BSWQ predictors was significant for the mixing cost, $F(3,34)=9.24, p<0.001$, and explained $42 \%$ (Adjusted $R^{2}=0.421$ ) of the variance. Language switching was a significant predictor of the mixing cost in this analysis: the more a participant tended to switch from Swedish to Finnish and vice versa, the smaller the mixing cost in errors in the Number-letter task was.

\section{DISCUSSION}

Given the somewhat controversial earlier results concerning the bilingual advantage in executive functions, we set out to explore this issue with a new, complementary approach where we sought for relationships between bilinguals' everyday language use and the level of their executive skills. In a sample of 38 FinnishSwedish early bilinguals, we found that the frequency with which our bilinguals switched between languages in their everyday life significantly predicted the mixing cost (error rate) in our set shifting task (Number-letter task). In broad terms, this result provides support for the assumption that the bilingual advantage stems from a lifelong experience in managing two languages that calls for executive resources (e.g., Green, 1998; Meuter and Allport, 1999; Rodriguez-Fornells et al., 2006; Abutalebi and Green, 2007; Colzato et al., 2008; Moreno et al., 2008; Bialystok et al., 2009; Ye and Zhou, 2009). Not surprisingly, we also found that age was significantly associated with both WM updating and the mixing cost in set shifting, so that younger bilinguals showed smaller processing costs. This is in line with the common finding 
Table 6 | Summary of the multiple regression analyses: BSWO variables as predictors of processing cost in RTs on the executive tasks.

\begin{tabular}{|c|c|c|c|c|c|}
\hline \multirow[t]{2}{*}{ Variable } & \multirow{2}{*}{$\begin{array}{l}\text { The Flanker effect } \\
\text { B }\end{array}$} & \multirow{2}{*}{$\begin{array}{l}\text { The Simon effect } \\
B\end{array}$} & \multirow{2}{*}{$\begin{array}{l}\text { The N-back effect } \\
B\end{array}$} & \multicolumn{2}{|c|}{ The number-letter task } \\
\hline & & & & $\begin{array}{l}\text { Switching cost } \\
B\end{array}$ & $\begin{array}{l}\text { Mixing cost } \\
B\end{array}$ \\
\hline Constant & $50.19^{*}$ & $71.70^{*}$ & 246.71 & $314.61^{*}$ & $812.66^{* *}$ \\
\hline Language switching & -1.87 & -1.78 & 7.92 & 6.08 & -21.12 \\
\hline Contextual switches & -0.30 & 0.42 & -8.01 & -11.15 & -10.09 \\
\hline$R^{2}$ & 0.17 & 0.02 & 0.06 & 0.04 & 0.22 \\
\hline$F$ & 2.33 & 0.28 & 0.61 & 0.43 & $2.91 *$ \\
\hline
\end{tabular}

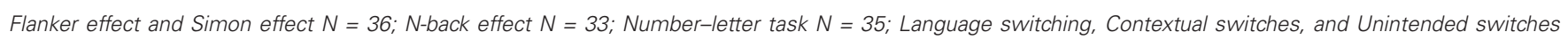
$N=38 .{ }^{*}=p<0.05,{ }^{*}=p<0.01$.

Table 7 | Summary of the multiple regression analyses: BSWO variables as predictors of processing cost in errors on the executive tasks.

\begin{tabular}{|c|c|c|c|c|c|}
\hline \multirow[t]{2}{*}{ Variable } & \multirow{2}{*}{$\begin{array}{l}\text { The Flanker effect } \\
\text { B }\end{array}$} & \multirow{2}{*}{$\begin{array}{l}\text { The Simon effect } \\
B\end{array}$} & \multirow{2}{*}{$\begin{array}{l}\text { The N-back effect } \\
\text { B }\end{array}$} & \multicolumn{2}{|c|}{ The number-letter task } \\
\hline & & & & $\begin{array}{l}\text { Switching cost } \\
B\end{array}$ & $\begin{array}{l}\text { Mixing cost } \\
B\end{array}$ \\
\hline Constant & $2.27^{*}$ & -0.38 & $21.05^{*}$ & -0.63 & $15.00 * *$ \\
\hline Language switching & $-0.19^{*}$ & -0.63 & -0.13 & 0.48 & $-0.62 * *$ \\
\hline Contextual switches & 0.07 & 0.14 & -1.19 & -0.02 & -0.28 \\
\hline$R^{2}$ & 0.16 & 0.03 & 0.13 & 0.05 & 0.47 \\
\hline$F$ & 2.17 & 0.39 & 1.49 & 0.53 & $9.24 * *$ \\
\hline
\end{tabular}

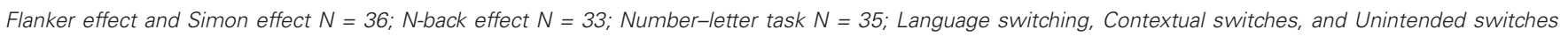
$N=38 .{ }^{*}=p<0.05,{ }^{* *}=p<0.01$.

that the efficiency of executive functions decreases in older age (e.g., Kramer et al., 1999; Kray et al., 2004; Zelazo et al., 2004; Takio et al., 2009).

While the present results are preliminary, they serve to highlight the potential of the complementary methodological approach we are introducing here. Previous studies showing enhanced executive functions in bilinguals have exclusively employed quasi-experimental designs (bilinguals vs. monolinguals) and have thus been unable to rule out all possible confounding factors that could contribute to the observed group differences (see, e.g., Morton and Harper, 2007). However, the present multiple regression approach focuses on the bilinguals and is thus not hampered by the unavoidable methodological problems of naturalistic group designs. Nevertheless, one must keep in mind that regression analyses represent a correlational approach and thus cannot prove causality.

In the present study, it was the mixing cost in the set shifting task that showed sensitivity to the bilingual experience. The underlying cognitive mechanisms of the mixing cost have been under debate. Rogers and Monsell (1995) proposed that the performance difference between single-task blocks and mixed-task blocks is due to an increased WM load, as two different task sets need to be maintained in the mixed-task blocks. However, Rubin and Meiran (2005) showed that the mixing cost is related to a top-down management of competing task sets, and not to WM load. The latter interpretation would fit in the present results: a task-decision process taking place in the mixed-tasks block resembles the bilingual situation where a decision of which language to use has to be made in each conversation.

It is not totally clear as to why we found associations between the bilingual language use and the mixing cost but not the switching cost in the set shifting task. It has, however, been suggested that the mixing cost and switching cost engage different cognitive control processes. The mixing cost may set more demands on sustained control processes, reflecting the constant need to keep different task-sets active or to maintain attentional monitoring processes, in order to efficiently react to changes in the task. The switching cost, on the other hand, may be related to transient control mechanisms, such as reconfiguration of goals or the linking of task cues to their appropriate stimulus-response mappings (Braver et al., 2003). The sustained and transient processes have also been suggested to activate different brain regions (Braver et al., 2003). Furthermore, studies have shown that the mixing cost increases at older age, while the switching cost is less affected by age (for a review, see Mayr and Liebscher, 2001). The switching cost has been defined as a measure of task-set reconfiguration (Rogers and Monsell, 1995), interference from the previous task-set (Allport et al., 1994), or a combination of both (Monsell, 2003; for a review, see Kiesel et al., 2010). The present results may thus give some clues as to exactly which aspects of bilingual language use are important for the executive gains: it might be that language selection and keeping both languages active 
are more important for the bilingual advantage than inhibition of the non-target language. This is in line also with the scanty associations between the predictors and the inhibition tasks (the single significant model explains only $15 \%$ of the variation of the Simon effect), although one should note that the Flanker task and the Simon task may not have been demanding enough for stronger relationships to appear. Contrary to the present findings, however, Prior and MacWhinney (2010) found a bilingual advantage in the switching cost, but not the mixing cost, in a study with young adults (see also Garbin et al., 2010).

One should also note that the present results showed an effect of language switching, but not contextual switches, on the mixing cost in the set shifting task. One possible reason for this may be that the questions in the language switching subscale concern language switching in general, i.e., whether the bilingual typically tends to use a word from the non-target language when the correct word in the target language cannot be retrieved quickly enough. It may be that this type of language switching is related to more sustained control processes, similar to the ones that have been suggested to be involved in the mixing cost. The contextual switches, on the other hand, may be more situation-bound, as the subscale includes questions as to whether there are specific situations and topics where the bilingual tends to mix both languages. This subscale does not give information about the frequency of occurrence for these situations in everyday life. Costa et al. (2009) speculates that those bilinguals who mostly use the two languages in different contexts and do not frequently switch between them, may not show an advantage in monitoring

\section{REFERENCES}

Abutalebi, J., and Green, D. (2007). Bilingual language production: the neurocognition of language representation and control. J. Neurolinguistics 20, 242-275.

Allport, A., Styles, E. A., and Hsieh, S. (1994). "Shifting intentional set: exploring the dynamic control of tasks," in Attention and Performance $X V$ : Conscious and Nonconscious Information Processing, eds C. Umilta and M. Moscovitch (Hillsdale, NJ: Erlbaum), 421-452.

Bialystok, E. (1999). Cognitive complexity and attentional control in the bilingual mind. Child Dev. 70, 636-644.

Bialystok, E. (2009). Bilingualism: the good, the bad, and the indifferent. Biling. Lang. Cogn. 12, 3-11.

Bialystok, E., Craik, F. I. M., Green, D. W., and Gollan, T. H. (2009). Bilingual minds. Psychol. Sci. Public Interest 10, 89-129.

Bialystok, E., Craik, F. I. M., Klein, R., and Viswanathan, M. (2004). Bilingualism, aging, and cognitive control: evidence from the Simon task. Psychol. Aging 19, 290-303.

Bialystok, E., Craik, F. I. M., and Luk, G. (2008). Cognitive control and lexical access in younger and older bilinguals. J. Exp. Psychol. Learn. Mem. Cogn. 34, 859-873.
Bialystok, E., Craik, F. I.M., and Ruocco,A. C. (2006a). Dual-modality monitoring in a classification task: the effects of bilingualism and ageing. Q. J. Exp. Psychol. 59, 1968-1983.

Bialystok, E., Craik, F. I. M., and Ryan, J. (2006b). Executive control in a modified antisaccade task: effects of aging and bilingualism. J. Exp. Psychol. Learn. Mem. Cogn. 32, 1341-1354.

Bialystok, E., and Majumder, S. (1998). The relationship between bilingualism and the development of cognitive processes in problem solving. Appl. Psycholinguist. 19, 69-85.

Bialystok, E., and Martin, M. M. (2004). children: evidence from the dimensional change card sort task. Dev. Sci. 7, 325-339.

Bialystok, E., and Viswanathan, M. (2009). Components of executive control with advantages for bilingual children in two cultures. Cognition $112,494-500$.

Braver, T. S., Reynolds, J. R., and Donaldson, D. I. (2003). Neural mechanisms of transient and sustained cognitive control during task switching. Neuron 39, 713-726.

Carlson, S. M., and Meltzoff,A.N. (2008). Bilingual experience and executive Sci. 11, 282-298. Attention and inhibition in bilingual functioning in young children. Dev.

processes, as they end up having less practice on language monitoring. The frequency of unintended switches did not predict executive performance either, probably because they reflect temporary processes that cause fluctuations in attentional control.

In summary, the present results provide some evidence that individual differences in bilingualism-related background factors may predict the mixing cost that bilinguals exhibit in a set shifting task. Our study presents a new, complementary methodological approach that will hopefully shed more light on the important issue of the relationships between bilingual experience and executive functions. There is no doubt that both the measurement of the various aspects of bilingual experience and the cognitive mechanisms of the mixing cost need to be clarified further in future studies. Ultimately, longitudinal data is needed to establish causal connections between bilingualism and enhanced cognition.

\section{ACKNOWLEDGMENTS}

This study was funded by a grant from the Joint Committee for Nordic Research Councils in the Humanities and the Social Sciences for a Nordic Center of Excellence (NCoE) in Cognitive Control (Coordinator Professor Lars Nyberg, Umeå University, Sweden). Anna Soveri was also supported by grants from Kommerserådet Otto A. Malms Donationsfond, and the Finnish National Doctoral Program of Psychology. Matti Laine was financially supported by the Academy of Finland. We would like to thank Teemu Laine for technical aid and Maria Pörnull for conducting part of the data collection.

Carlsson, S., Martinkauppi, S., Rama, P., Salli, E., Kovenoja, A., and Ahonen, HJ. (1998). The distribution of cortical activation during visuospatial $n$-back tasks as revealed by functional magnetic resonance imaging. Cereb. Cortex $8,743-752$.

Colzato, L. S., Bajo, M. T., van den Wildenberg, W., Paolieri, D. Nieuwenhuis, S., Heij, W. L., and Hommel, B. (2008). How does bilingualism improve executive control? A comparison of active and reactive inhibition mechanisms. J. Exp. Psychol Learn. Mem. Cogn. 34, 302-312.

Costa, A., Hernández, M., Costa-Faidella, J., and Sebastián-Gallés, N. (2009). On the bilingual advantage in conflict processing: now you see it, now you don't. Cognition 113, 135-149.

Costa, A., Hernández, M., and SebastiánGallés, N. (2008). Bilingualism aids conflict resolution: evidence from the ANT task. Cognition 106, 59-86.

Eriksen, B. A., and Eriksen, C. W. (1974) Effects of noise letters upon the identification of a target letter in a nonsearch task. Percept. Psychophys. 16, 143-149.

Friedman, N. P., and Miyake, A. (2004). The relations among inhibition and interference cognitive functions: a latent variable analysis. J. Exp. Psychol. Gen. 133, 101-135.
Friedman, N. P., Miyake, A., Corley, R. P., Young, S.E., DeFries, J.C., and Hewitt, J. K. (2006). Not all executive functions are related to intelligence. Psychol. Sci. 17, 172-179.

Garbin, G., Sanjuan, A., Forn, C., Bustamante, J. C., RodriguezPujadas, A., Belloch, V., Hernandez, M., Costa, A., and Ávila, C. (2010). Bridging language and attention: brain basis of the impact of bilingualism on cognitive control. Neuroimage 53, 1272-1278.

Gratton, G., Coles, M. G.H., and Donchin, E. (1992). Optimizing the use of information: strategic control of activation of responses. J. Exp. Psychol. Gen. 121, 480-506.

Green, D. W. (1998). Mental control of the bilingual lexico-semantic system. Biling. Lang. Cogn. 1, 67-81.

Kiesel, A., Steinhauser, M., Wendt, M., Falkenstein, M., Jost, K., Philipp, A. M. and Koch, I. (2010). Control and interference in task switching - A review. Psychol. Bull. 136, 849-874.

Kramer, A. F., Hahn, S., and Gopher, D. (1999). Task coordination and aging: explorations of executive control processes in the task switching paradigm. Acta Psychol. (Amst.) 101, 339-378.

Kray, J., Eber, J., and Lindenberger, U. (2004). Age differences in executive functioning across the lifespan: 
the role of verbalization in task preparation. Acta Psychol. (Amst.) 115, 143-165.

Lezak, M. D. (1995). Neuropsychological Assessment. New York: Oxford University Press, Inc.

Martin-Rhee, M. M., and Bialystok, E. (2008). The development of two types of inhibitory control in monolingual and bilingual children. Biling. Lang. Cogn. 11, 81-93.

Mayr, U., and Liebscher, T. (2001). Is there an age deficit in the selection of mental sets? Eur. J. Cogn. Psychol. 13, 47-69.

Meuter, R. F. I., and Allport, A. (1999). Bilingual language switching in naming: asymmetrical costs of language selection. J. Mem. Lang. 40, 25-40.

Miyake, A., Friedman, N. P., Emerson, M. J., Witzki, A. H., and Howerter, A. (2000). The unity and diversity of executive functions and their contributions to complex "frontal lobe" tasks: a latent variable analysis. Cogn. Psychol. 41, 49-100.

Monsell, S. (2003). Task switching. Trends Cogn. Sci. (Regul. Ed.) 7, 134-140.
Moreno, E. M., Rodriguez-Fornells, A., and Laine, M. (2008). Event-related potentials (ERPs) in the study of bilingual language processing. $J$. Neurolinguistics 21, 477-508.

Morton, J. B., and Harper, S. N. (2007). What did Simon say? Revisiting the bilingual advantage. Dev. Sci. 10, 719-726.

Namazi, M., and Thordardottir, E. (2010). A working memory, not bilingual advantage, in controlled attention. Int. J. Biling. Educ. Biling. 13, 597-616.

Oldfield, R.C. (1971). The assessment and analysis of handedness: the Edinburg Inventory. Neuropsychologia 9,97-113.

Prior, A., and MacWhinney, B. (2010). A bilingual advantage in task switching. Biling. Lang. Cogn. 13, 253-262.

Rodriguez-Fornells, A., de Diego Balaguer, R., and Münte, TF. (2006). Executive functions in bilingual language processing. Lang. Learn. 56, 133-190.

Rogers, R. D., and Monsell, S. (1995). Costs of a predictable switch between simple cognitive tasks. J. Exp. Psychol. Gen. 124, 207-231.
Rubin, O., and Meiran, N. (2005). On the origins of the task mixing cost in the cuing task-switching paradigm. J. Exp. Psychol. Learn. Mem. Cogn. 31, 1477-1491.

Simon, J. R., and Rudell, A. P. (1967) Auditory S-R compatibility: the effect of an irrelevant cue on information processing. J. Appl. Psychol.51, 300-304.

Soveri, A., Laine, M., Hämäläinen, H., and Hugdahl, K. (2011). Bilingual advantage in focused attention: evidence from the forced-attention dichotic listening paradigm. Biling. Lang. Cogn. 14, 371-378.

Takio, F., Koivisto, M., Jokiranta, L., Rashid, F., Kallio, J., Tuominen, T. Laukka, S., and Hämäläinen, H. (2009). The effect of age on attentional modulation in dichotic listening. Dev. Neuropsychol. 34, 225-239.

Ye, Z., and Zhou, X. (2009). Executive control in language processing. Neurosci. Biobehav. Rev. 33, 1168-1177.

Zelazo, P. D., Craik, F. I. M., and Booth, L. (2004). Executive function across the life span.ActaPsychol. (Amst.) 115, 167-183.
Conflict of Interest Statement: The authors declare that the research was conducted in the absence of any commercial or financial relationships that could be construed as a potential conflict of interest.

Received: 01 March 2011; accepted: 21 July 2011; published online: 01 August 2011. Citation: Soveri A, Rodriguez-Fornells A and Laine $M$ (2011) Is there a relationship between language switching and executive functions in bilingualism? Introducing a within-group analysis approach. Front. Psychology 2:183. doi: 10.3389/ fpsyg.2011.00183

This article was submitted to Frontiers in Cognition, a specialty of Frontiers in Psychology.

Copyright $\odot 2011$ Soveri, Rodriguez-Fornells and Laine. This is an open-access article subject to a non-exclusive license between the authors and Frontiers Media SA, which permits use, distribution and reproduction in other forums, provided the original authors and source are credited and other Frontiers conditions are complied with. 